\title{
Effects of fishing on fish assemblages at the reefscape scale
}

\author{
B. M. Fitzpatrick ${ }^{1, *}$, E. S. Harvey ${ }^{2}$, T. J. Langlois ${ }^{3}$, R. Babcock ${ }^{4}$, E. Twiggs ${ }^{2}$ \\ ${ }^{1}$ Oceanwise Australia, Floreat, Perth, Western Australia 6014, Australia \\ ${ }^{2}$ Curtin University of Technology, Kent St., Perth, Western Australia 6012, Australia \\ ${ }^{3}$ The Oceans Institute, University of Western Australia, 35 Stirling Highway, Crawley, Western Australia 6009, Australia \\ ${ }^{4}$ Commonwealth Science and Industrial Research Organisation, PO Box 120, Cleveland, Queensland 4163, Australia
}

\begin{abstract}
We studied the persistence of fishing impacts on coral reef fish assemblages by sampling 2 protected and 2 fished locations, using random replicate stereo baited remote underwater video. At each location we sampled a variety of coral reef habitats on 4 separate occasions between 2006 and 2007. We tested for consistency in differences in the biomass of target and nontarget species, trophic groups and overall assemblages. Generally, target species were more abundant and/or larger at protected locations. Many non-target species were either more abundant or depleted at protected sites, and some of these species were significantly larger or smaller. Trophic groups such as piscivores, piscivore invertivores, invertivores and planktivores were consistently more abundant within protected locations. Generally, greater numbers of species and individuals were found on protected reefs, though this was not consistent in all cases across all 4 sampling periods. These findings are consistent with the theory that protected areas can increase the abundance of not just target species but overall fish assemblages. These findings provide evidence for ecological mechanisms such as predator-prey interactions, competitive release, and benefits to invertivores, omnivores and other non-target groups from the presence of more abundant and larger target species within marine protected areas.
\end{abstract}

KEY WORDS: Marine protected areas $\cdot$ Ningaloo Reef $\cdot$ Fishery $\cdot$ Coral reef

\section{INTRODUCTION}

Direct benefits of no-take areas include increased abundance, density, mean length and biomass of species targeted by fishermen (Russ et al. 2008). The preservation or recovery of target fish populations allows the persistence of the ecological interactions they are involved in, such as predation (Hixon \& Jones 2005, Mumby et al. 2006). The presence of more abundant and bigger target species affects the abundance of the non-target species they interact with, such as pomacentrid fishes that are preyed upon by piscivorous serranids (Shears \&
Babcock 2002, Graham et al. 2003, Watson et al. 2007).

Coral reef fish assemblages are strongly influenced by variation in biophysical habitats (Friedlander \& Parrish 1998), which interact with and mediate biological signals associated with the effects of fishing (Friedlander et al. 2007). Coral reef fish assemblage structure varies with processes including recruitment, feeding and migration that are all closely linked to temporal cues (Doherty et al. 1994, Sadovy \& Domeier 2005). It is therefore important to test the generality of the effects of fishing on overall fish assemblage structure repeatedly through time. 
Pollution and disturbance caused by terrestrial development, climate change and other human impacts also affect the structure of coral reef fish assemblages (Wilson et al. 2008). There are very few extant coral reef systems that are not subjected to multiple human impacts, making it difficult to attribute variation to any single factor.

Many studies on direct and indirect effects of fishing have had low levels of spatial and temporal replication (Willis et al. 2003). This study accounts for some of the sources of variation in fish assemblages by quantifying the possible responses of coral reef fish assemblages to protection. A comparison of variation in overall fish assemblage structure within and adjacent to 2 long established sanctuary zones (Mandu and Osprey) at Ningaloo Reef in Western Australia was made on 4 occasions. This fringing reef system, adjacent to the remote, arid North West Cape of Western Australia, is a relatively pristine coral reef ecosystem that is, however, subject to seasonally high recreational fishing effort, and affected by historical commercial fishing impacts. Fishing was the only significant human impact known at this particular location at the date of sampling. This coral reef has escaped impacts linked to global climate change, polluted runoff and overpopulation, and other human impacts that are common elsewhere.

Within these 2 protected areas, the relative abundance of target species relative to adjacent fished habitats has increased (Westera et al. 2003). The most heavily targeted species, including Lethrinus nebulosus, Le. atkinsoni, Epinephelus rivulatus, Carangoides fulvoguttatus, and to a lesser extent Lutjanus carponotatus, Lu. fulviflamma, and Gnathanodon speciosus are more abundant and/or larger at protected habitats. Most of these species are higher order predators that are either piscivores or piscivore-invertivores.

The main aim of this study was to test whether the abundance, length and biomass of fish assemblages differ consistently among multiple protected and fished reefscapes, and to determine whether these differences are persistent through time. The reefscape scale is equivalent to landscape in terrestrial environments and is composed of predictable spatial patterns in the distribution of coral reef habitats (see Arias-Gonzalez et al. 2006). We tested the hypothesis that protection will affect abundance and length of non-target species in addition to those directly targeted by fishers. We tested for patterns in the abundance and length of target and non-target species, trophic groups and overall assemblage structure that were persistent through time, and considered the extent to which consistency of these patterns provided evidence of effects from fishing on overall fish assemblage structure.

\section{MATERIALS AND METHODS}

\section{Survey design}

To account for the variation in fish assemblages driven by differences in habitat, replicate stereobaited remote underwater video (stereo-BRUV) samples were collected. Stereo-BRUVs are particularly useful for assessing fish assemblages for the effects of fishing (Shortis \& Harvey 1998, Cappo et al. 2003, Harvey et al. 2004, Watson et al. 2005, Langlois et al. 2010, Watson et al. 2010). Stereo-BRUV samples were stratified by broad habitat types representative of the variation in habitat (Cassata \& Collins, 2008). Habitat had been previously mapped using rectified and ground truthed aerial and hyperspectral imagery and included (1) subtidal reef pavement, (2) lagoon Porites coral 'bommies', (3) lagoon patch reefs, (4) tabulate Acropora-dominated inner reef flat, (5) outer coral-algal reef flat and (6) reef pass zones. These habitat types account for a majority of the variation in fish assemblages (Wilson et al. 2012). To account for temporal variation in these fish assemblages, the same protected and fished assemblages were resampled 4 times during 2006 and 2007. Each time, 6 random stereo-BRUV replicates were collected from each of the 6 protected and fished habitats at each of the 2 locations, resulting in a total of 576 stereo-BRUV replicates (Fig. 1).

\section{Image analysis}

Each stereo-BRUV tape was read for fish presence with the tape reader recording the maximum number of individuals of the same species seen together at any one time on the whole tape (MaxN) (Cappo et al. 2003, 2004). Stereo-video measurements including fork length of fish and distances and direction from the camera were taken from each stereo-BRUV tape pair using PhotoMeasure at the time of MaxN (for details see Watson et al. 2007 and www.seagis.com. $\mathrm{au}$ ). Data were standardized for minimum visibility, eliminating fish $>6 \mathrm{~m}$ away from the cameras and resulting in a standardized sampling area of $37.22 \mathrm{~m}^{2}$ and volume of $276.35 \mathrm{~m}^{2}$ (Harvey et al. 2004). Length estimates $>5 \%$ inaccurate were omitted (Watson et al. 2007). Length data for rare and/or large bodied 


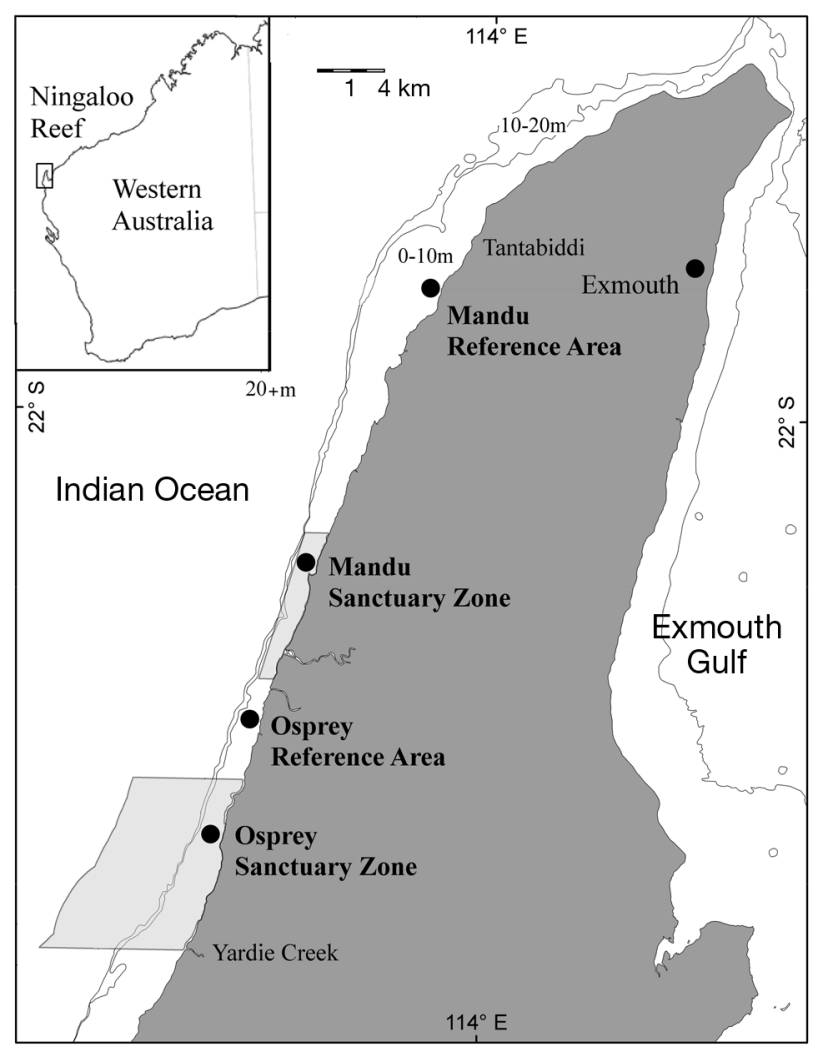

Fig. 1. Study area on the coast of the North West Cape of Western Australia, showing location of sampling sites within Osprey and Mandu sanctuary zones and adjacent reference areas

species were omitted from the calculation of mean length since these random events may influence statistical tests incommensurately with their relevance. These omissions included data on all species of elasmobranchs, large Epinephelus tukula and E. lanceolatus, and Gymnothorax, Scomberomorus and Tylosurus species.

\section{Data analysis}

Multivariate abundance and length data

A 3-way PERMANOVA (Anderson et al. 2008) was used to test differences in fish assemblages between the 3 factors Time (4 levels fixed: Time 1, 2, 3 and 4), Location (2 levels fixed: Mandu and Osprey) and Protection (2 levels fixed: fished and protected). Time was considered a fixed factor; this is a more conservative approach than considering Time as a random factor as it accounts for potential seasonal or temporal patterns in the data. For each term in the analysis, 4999 permutations based on modified Gower $\log _{10}$ for multivariate fish abundance or length matrices were computed to obtain p-values (Anderson \& Millar 2004). Matrices analysed included species, target species, non-target species and trophic groups. Fish were assigned to broad trophic groups based on dietary and ecological data from Fishbase and included piscivores, piscivore-invertivores, invertivores, omnivores, corallivores, herbivores and planktivores (Froese \& Pauly 2014).

To test for the consistency of patterns of species composition among the 16 Protection $\times$ Location $\times$ Time comparisons, a constrained canonical analysis of principal coordinates analysis was applied (CAP) (Anderson \& Robinson 2003, Anderson \& Willis 2003). Species with a correlation $R>0.3$ with CAP axis 1 or 2 were identified by this procedure as being responsible for driving any significant differences in fish assemblages in relation to the treatments. The mean abundance and length of the species identified by the CAP analyses were then calculated over all habitats over 4 sampling times for graphical display.

Centroids of the mean abundance and mean length of multivariate species, target species, non-target species and trophic group data were computed for all replicates from each Protection $\times$ Location $\times$ Time combination. These centroid values were then used to compute a distance matrix among all 16 Protection $\times$ Location $\times$ Time comparisons from which non-metric multiple dimensional scaling (NMDS) plots were constructed. These NMDS plots are a 2 or 3 dimensional representation of the multidimensional data cloud composed of the 16 treatment combinations.

\section{Univariate abundance, length and biomass data}

A univariate analysis of mean abundance (ind. BRUV $\left.^{-1}\right)$, mean length $(\mathrm{cm})$ and mean biomass $(\mathrm{kg})$ was undertaken with ANOVA using a modified Gower $\log _{10}$ matrix and the same model as described for the multivariate analysis above. To derive biomass, length estimates were combined with published length $\times$ weight relationships from Fishbase to derive mean biomass estimates for each species (Froese \& Pauly 2014). If a particular species length $\times$ weight relationship was not known, parameters of a closely related and morphometrically similar species were substituted. In addition to those large rare species omitted from the length data analysis listed above, large schools of kyphosid species sighted on 3 stereo-BRUVs were omitted from the biomass analysis, as these data created biomass estimates orders of magnitude greater than elsewhere. 


\section{RESULTS}

\section{Species differences}

Mean abundance was significantly different between levels of Protection and Time and there was also a significant interaction between these 2 factors (Table 1). Despite significant differences through time at each location, temporal variation did not supersede the pattern of distinct fish assemblages associated with each habitat type between fished

Table 1. Results of 3-way PERMANOVA of mean abundance of coral reef fish assemblages at 2 locations in Western Australia (2 levels fixed) containing fished and protected areas (2 levels nested in Location), sampled on 4 separate occasions during 2006-2007. Data was modified Gower $\log _{10}$ transformed, using 4999 permutations. See Table 4 for lists of target and non-target species. Lo: location; Ti: time; Pr: protection; Res: Residual. $\mathrm{p}<0.05$ in bold

\begin{tabular}{|c|c|c|c|c|c|}
\hline Factors & df & SS & MS & Pseudo- $F$ & $\mathrm{p}$ \\
\hline \multicolumn{6}{|l|}{ Species } \\
\hline Lo & 1 & 2.7456 & 2.7456 & 0.65012 & 0.9638 \\
\hline $\mathrm{Ti}$ & 3 & 6.742 & 2.2473 & 1.7563 & 0.001 \\
\hline $\operatorname{Pr}(\mathrm{Lo})$ & 2 & 8.4475 & 4.2237 & 6.6366 & 0.001 \\
\hline $\operatorname{Pr}(\mathrm{Lo}) \times \mathrm{Ti}$ & 6 & 7.6919 & 1.282 & 2.0143 & 0.001 \\
\hline Res & 496 & 315.67 & 0.63643 & & \\
\hline Total & 511 & 345.49 & & & \\
\hline \multicolumn{6}{|c|}{ Target species } \\
\hline Lo & 1 & 2.15 & 2.15 & 0.46 & 0.993 \\
\hline $\mathrm{Ti}$ & 3 & 6.30 & 2.10 & 1.51 & 0.009 \\
\hline $\operatorname{Pr}(\mathrm{Lo})$ & 2 & 9.42 & 4.71 & 8.48 & 0.001 \\
\hline $\operatorname{Pr}(\mathrm{Lo}) \times \mathrm{Ti}$ & 6 & 8.38 & 1.40 & 2.51 & 0.001 \\
\hline Res & 496 & 275.64 & 0.56 & & \\
\hline Total & 511 & 305.82 & & & \\
\hline \multicolumn{6}{|c|}{ Non-target species } \\
\hline Lo & 1 & 2.75 & 2.75 & 0.78 & 0.798 \\
\hline $\mathrm{Ti}$ & 3 & 6.60 & 2.20 & 1.70 & 0.001 \\
\hline $\operatorname{Pr}(\mathrm{Lo})$ & 2 & 7.05 & 3.52 & 5.39 & 0.001 \\
\hline $\operatorname{Pr}(\mathrm{Lo}) \times \mathrm{Ti}$ & 6 & 7.76 & 1.29 & 1.98 & 0.001 \\
\hline Res & 496 & 324.12 & 0.65 & & \\
\hline Total & 511 & 352.47 & & & \\
\hline \multicolumn{6}{|c|}{ Trophic groups } \\
\hline Lo & 1 & 1.21 & 1.21 & 0.54 & 0.75 \\
\hline $\mathrm{Ti}$ & 3 & 5.78 & 1.93 & 3.79 & 0.001 \\
\hline $\operatorname{Pr}(\mathrm{Lo})$ & 2 & 4.498 & 2.25 & 5.03 & 0.001 \\
\hline $\operatorname{Pr}(\mathrm{Lo}) \times \mathrm{Ti}$ & 6 & 3.06 & 0.51 & 1.14 & 0.2786 \\
\hline Res & 496 & 221.73 & 0.45 & & \\
\hline Total & 511 & 239.11 & & & \\
\hline \multicolumn{6}{|c|}{ Overall (univariate ANOVA) } \\
\hline Lo & 1 & 27979 & 27979 & 0.99 & 0.438 \\
\hline $\mathrm{Ti}$ & 3 & 24180 & 8060 & 0.56 & 0.661 \\
\hline $\operatorname{Pr}(\mathrm{Lo})$ & 2 & 56713 & 28356 & 4.33 & 0.014 \\
\hline $\operatorname{Pr}(\mathrm{Lo}) \times \mathrm{Ti}$ & 6 & 85793 & 14299 & 2.18 & 0.043 \\
\hline Res & 496 & $3.2 \times 10^{6}$ & 6547 & & \\
\hline Total & 511 & $3.5 \times 10^{6}$ & & & \\
\hline
\end{tabular}

and protected locations (Fig. 2). The dominant species contributing to these patterns (Fig. 3) are discussed below. The variability contributed by temporal sampling did not supersede effects of fishing (Fig. 4). The mean length of species was significantly different between levels of Protection, though the effect of Protection was confounded by an interaction with Time (Table 2). Although there was temporal variation in the average length of all fish in assemblages within locations, in the majority of instances overall biomass of fish assemblages was significantly greater within sanctuary zones compared to adjacent fished sites (Fig. 5). The mean abundance and length of species was not significantly different between the Osprey and Mandu locations.

\section{Target species}

The mean abundances of target species were significantly different between the 2 levels of Protection, Time, Location, and for the Protection $\times$ Time interaction (Table 1). The abundance of the main target species was generally higher at protected reefscapes (fished: $8 \pm 0.59$, mean \pm SE; protected: $14.5 \pm$ 0.91), however this was confounded by Protection $x$ Time interactions. The mean length of target species was significantly different between protected and fished locations (fished: $297 \pm 7 \mathrm{~mm}$; protected: $309 \pm$ $3 \mathrm{~mm}$ ). The mean abundances of Epinephelus rivulatus, Lethrinus atkinsoni, Le. nebulosus and Carangoides fulvoguttatus were positively correlated to protection (Fig. 3, Appendix 1). The mean lengths of Le. atkinsoni, Le. nebulosus and E. rivulatus were greater at protected locations (Fig. 3, Appendix 1). Despite the confounding significant interaction between time and protection, the length and abundance of target species showed clear differentiation between protected and fished sites, over and above the less variable effects of time (Figs. 5 \& 6).

\section{Non-target species}

The mean abundance and length of non-target species were significantly different between levels of protection and times, and there was also a significant interaction between these 2 factors (Table 1). The abundances of Scarus rubroviolaceous, Kyphosus sp., Thallasoma sp., Dascyllus aruanus, Pomacentrus coelestis, Chromis viridis, Abudefduf sexfaciatus, Acanthurus grammoptilus, Labroides dimidiatus, Chlorurus sordidus and Parupeneus 

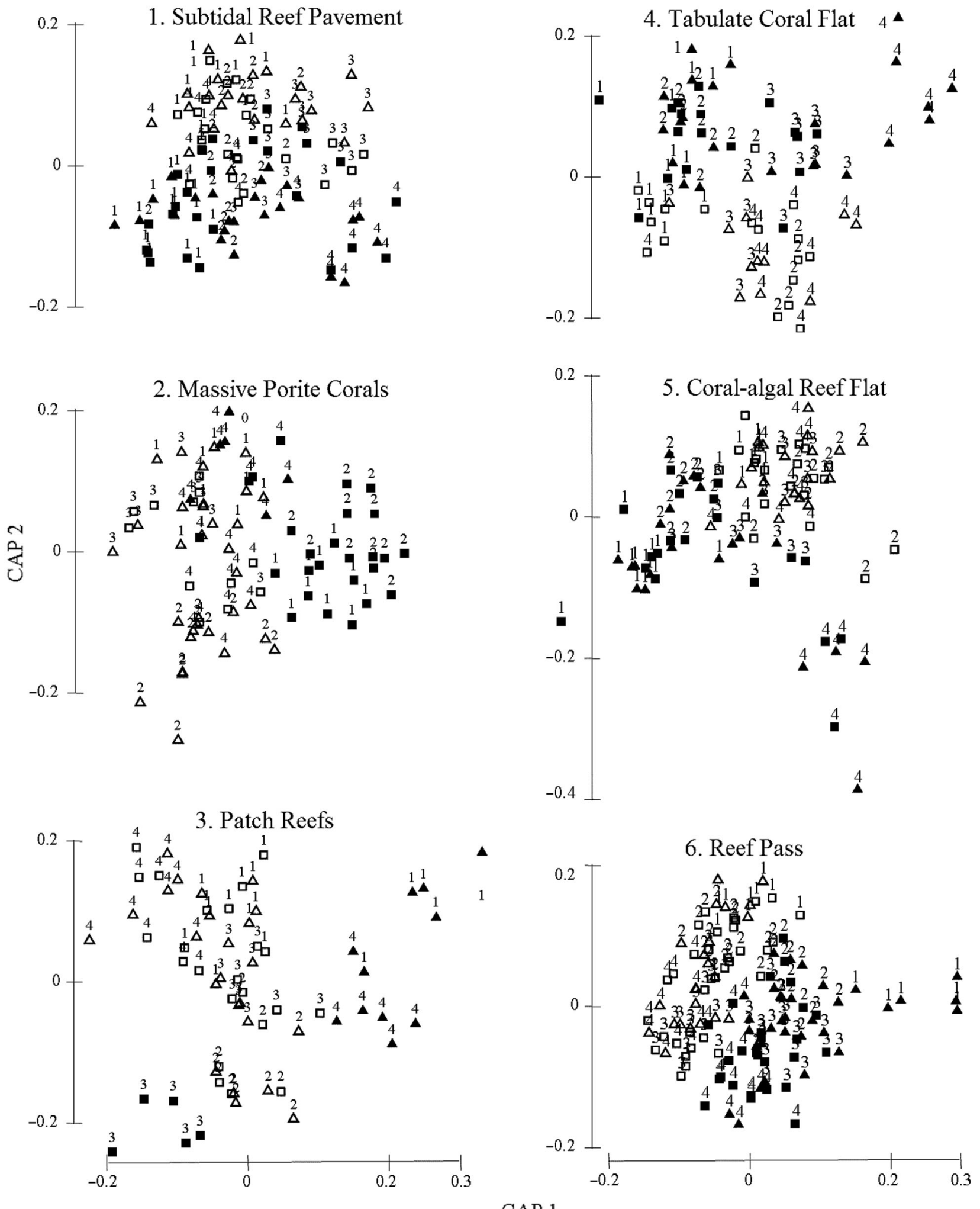

CAP 1

Fig. 2. Canonical analysis of principal coordinates (CAP) analysis of modified Gower $\log _{10}$ transformed mean abundance of all fish in 6 habitat types at 2 protected locations in Western Australia and 2 adjacent fished reference areas: $(\Delta)$ Mandu reference area; ( $\mathbf{\Delta})$ Mandu Sanctuary Zone; $(\square)$ Osprey reference area; ( $\mathbf{\square})$ Osprey Sanctuary Zone. Sampling was on 4 occasions during 2006-2007 (numbers 1-4). In all cases a significant difference between protected and fished assemblages was detected 


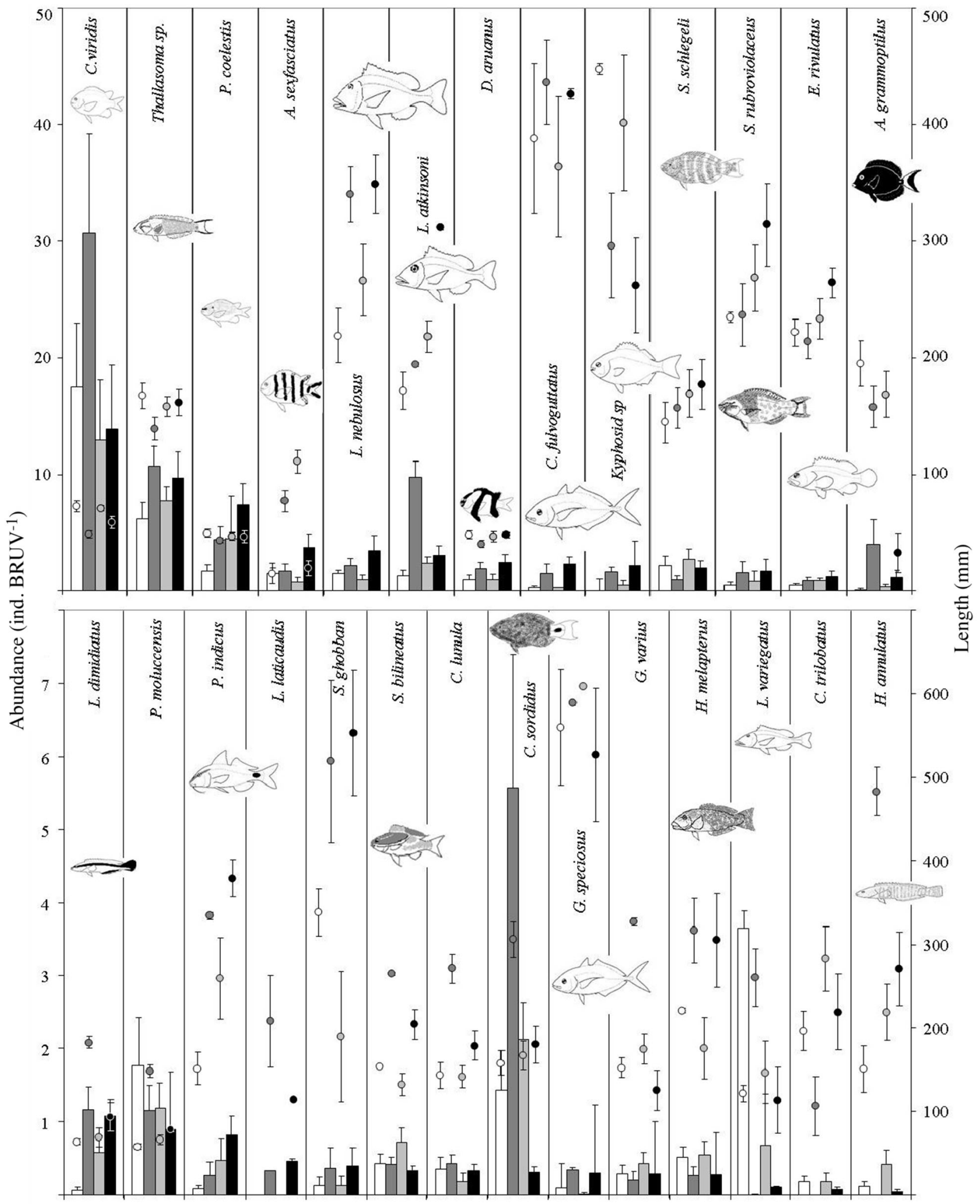

Fig. 3. Abundance and length (mean $\pm \mathrm{SE}$ ) of fish at fished and protected reefscapes averaged over 4 sampling periods in 2006-2007. White, dark grey, light grey and black bars and circles represent mean abundance and mean length at Mandu reference area, Mandu Sanctuary Zone, Osprey reference area and Osprey Sanctuary Zone, respectively. BRUV: baited remote underwater video 

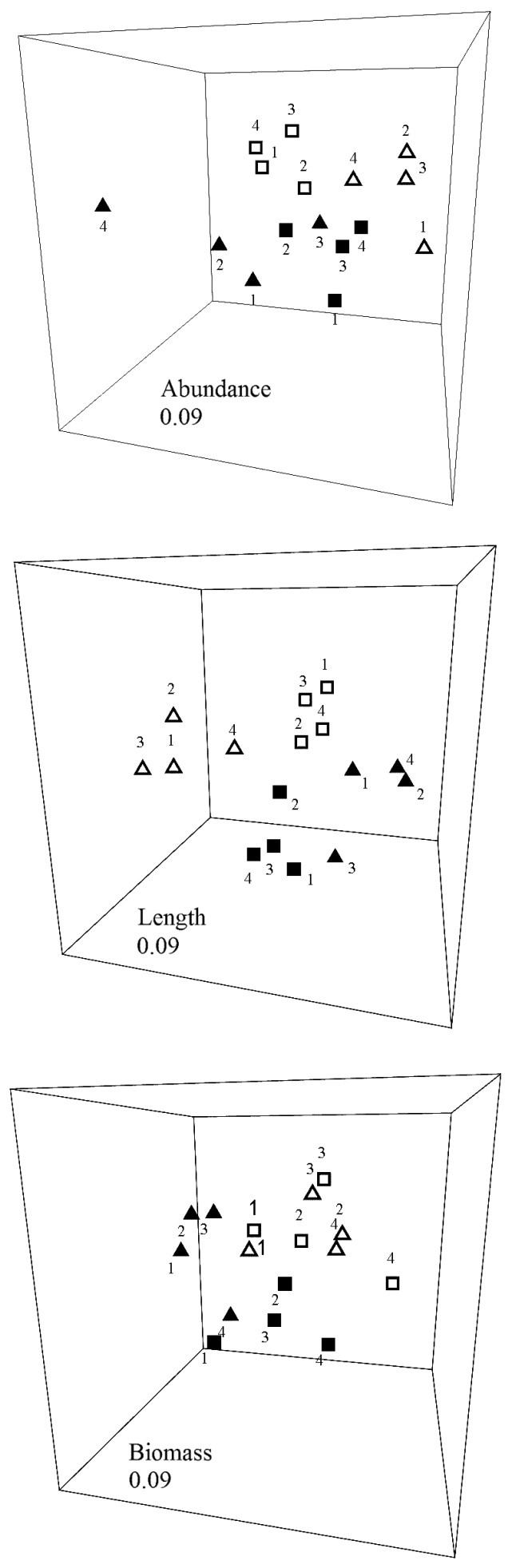

Fig. 4. Non-metric multiple dimensional scaling (NMDS) based on (top) centroid mean abundance $\left(\mathrm{BRUV}^{-1}\right)$, (centre) length (mm) and (bottom) biomass (kg) of fish at 2 fished (open symbols) and 2 protected areas (shaded symbols) on 4 separate occasions during 2006-2007 (numbers 1-4). For key to symbols see Fig. 2 legend. 3D MDS stress is indicated
Table 2. Results of 3-way PERMANOVA of effects of protection on mean length in coral reef fish. $\mathrm{p}<0.05$ in bold. For details see Table 1 legend

\begin{tabular}{|c|c|c|c|c|c|}
\hline Factors & df & SS & MS & Pseudo- $F$ & $\mathrm{p}$ \\
\hline \multicolumn{6}{|l|}{ Species } \\
\hline Lo & 1 & 11.426 & 11.426 & 0.537 & 0.997 \\
\hline $\mathrm{Ti}$ & 3 & 31.21 & 10.403 & 1.743 & 0.001 \\
\hline $\operatorname{Pr}(\mathrm{Lo})$ & 2 & 42.531 & 21.266 & 5.443 & 0.001 \\
\hline $\operatorname{Pr}(\mathrm{Lo}) \times \mathrm{Ti}$ & 6 & 35.849 & 5.9748 & 1.53 & 0.001 \\
\hline Res & 412 & 1609.8 & 3.9072 & & \\
\hline Total & 427 & 1748.6 & & & \\
\hline \multicolumn{6}{|c|}{ Target species } \\
\hline Lo & 1 & 3.34 & 3.34 & 0.08 & 0.992 \\
\hline $\mathrm{Ti}$ & 3 & 25.79 & 8.6 & 1.69 & 0.106 \\
\hline $\operatorname{Pr}(\mathrm{Lo})$ & 2 & 89.62 & 44.81 & 12.77 & 0.001 \\
\hline $\operatorname{Pr}(\mathrm{Lo}) \times \mathrm{Ti}$ & 6 & 30.56 & 5.09 & 1.45 & 0.051 \\
\hline Res & 412 & 1446 & 3.51 & & \\
\hline Total & 427 & 1612.5 & & & \\
\hline \multicolumn{6}{|c|}{ Non-target species } \\
\hline Lo & 1 & 12.691 & 12.691 & 0.76833 & 0.8622 \\
\hline $\mathrm{Ti}$ & 3 & 31.929 & 10.643 & 1.8805 & 0.001 \\
\hline $\operatorname{Pr}(\mathrm{Lo})$ & 2 & 33.038 & 16.519 & 4.2534 & 0.001 \\
\hline $\operatorname{Pr}(\mathrm{Lo}) \times \mathrm{Ti}$ & 6 & 33.993 & 5.6655 & 1.4588 & 0.001 \\
\hline Res & 412 & 1600.1 & 3.8837 & & \\
\hline Total & 427 & 1728.7 & & & \\
\hline \multicolumn{6}{|c|}{ Trophic groups } \\
\hline Lo & 1 & 2.12 & 2.13 & 0.50 & 0.781 \\
\hline $\mathrm{Ti}$ & 3 & 10.9 & 3.64 & 3.11 & 0.004 \\
\hline $\operatorname{Pr}($ Lo $)$ & 2 & 8.55 & 4.28 & 3.25 & 0.001 \\
\hline LoxTi & 3 & 7.85 & 2.62 & 2.24 & 0.032 \\
\hline $\operatorname{Pr}(\mathrm{Lo}) \times \mathrm{Ti}$ & 6 & 7.02 & 1.17 & 0.89 & 0.633 \\
\hline Res & 412 & 542.89 & 1.32 & & \\
\hline Total & 427 & 579.81 & & & \\
\hline \multicolumn{6}{|c|}{ Overall (univariate ANOVA) } \\
\hline Lo & 1 & 26616 & 26616 & 3.15 & 0.205 \\
\hline $\mathrm{Ti}$ & 3 & $1.3 \times 10^{5}$ & 43767 & 2.61 & 0.137 \\
\hline $\operatorname{Pr}(\mathrm{Lo})$ & 2 & 16909 & 8454.7 & 0.86 & 0.427 \\
\hline $\operatorname{Pr}(\mathrm{Lo}) \times \mathrm{Ti}$ & 6 & $1.0 \times 10^{5}$ & 16785 & 1.71 & 0.108 \\
\hline $\operatorname{Res}$ & 412 & $4.0 \times 10^{6}$ & 9788.6 & & \\
\hline Total & 427 & $4.4 \times 10^{6}$ & & & \\
\hline
\end{tabular}

indicus were positively correlated to protected locations (Fig. 3, Appendix 1). The abundances of Le. variegates, Scarus schlegeli, Pomacentrus moluccensis, Hemigymnus melapterus, Hologymnosus annulatus and Cheilinus trilobatus, were positively correlated to fished locations. The abundances of Scolopsis bilineatus, Chaetodon lunula and Gomphosus varius varied in response to protection. La. dimidiatus, Che. trilobatus, Ho. annulatus and $\mathrm{Pa}$. indicus were significantly larger at protected locations while Chl. sordidus, Chr. viridis and Kyphosus sp. were significantly smaller at protected locations. The length of He. melapterus varied in response to protection. Although effects of 


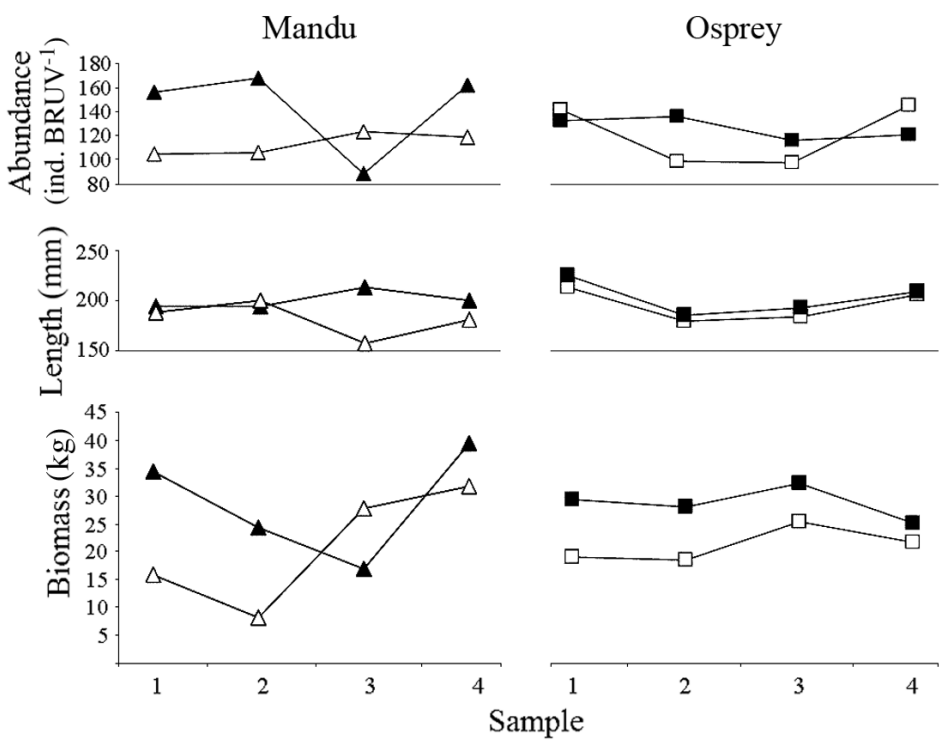

Fig. 5. Mean abundance, length and biomass of species significantly correlated to differences between 2 fished (open symbols) and 2 protected reef habitats (shaded symbols) on 4 occasions during 2006-07 (numbers 1-4). For key to symbols showing locations see Fig. 2 legend

protection from fishing were significant, the variability introduced by temporal sampling was considerable (Fig. 6). The length and abundance of non-target species were not significantly different between the 2 locations.

\section{Overall assemblage structure}

The univariate abundance of fishes was not significantly different between the 2 locations. It was significantly different between Time, levels of Protection and Protection $\times$ Time interactions (Table 1). The mean abundance of all fish was significantly higher within protected habitats (fished: $78 \pm 4.8$, mean \pm

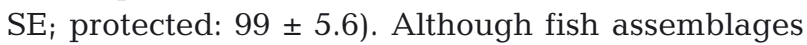
were significantly different each time they were measured, there were consistent differences in abundance between fished and protected assemblages (Figs. 4 \& 5). The mean length of all fish did not differ between Location, Time or levels of Protection (Tables 2 \& 3). Overall biomass differed significantly between fished and protected assemblages (Table 3). This difference was generally consistent between locations (Figs. 5 \& 6).

\section{DISCUSSION}

Although fish assemblages were significantly different each time they were measured, this did not obscure consistent differences between fished and protected reefscapes. Average abundance, length and biomass of fish assemblages were driven by more and larger target species as well as significant differences in the abundance and length of non-target species. Generally, fish in protected fish assem-

\section{Trophic groups}

The mean abundance and length of trophic groups were not significantly different between the 2 locations; however they were significantly different between levels of Protection and Time (Tables $1 \& 2$ ). The length of trophic groups was confounded by a Protection $\times$ Time interaction (Tables 1 $\& 2)$. Some trophic groups were consistently more abundant within protected locations. This included targeted piscivores, piscivore invertivores (fished: $2.54 \pm 0.24$, mean $\pm \mathrm{SE}_{\text {; }}$ protected: $4.11 \pm 0.35)$, non-targeted invertivores (fished: $2.6 \pm 0.10$; protected: $3.4 \pm$ 0.14 ) and planktivores (Figs. 6 \& 7). Piscivores and piscivore invertivores were larger at protected locations and this was consistent through time compared to assemblages quantified at fished locations (Fig. 8).

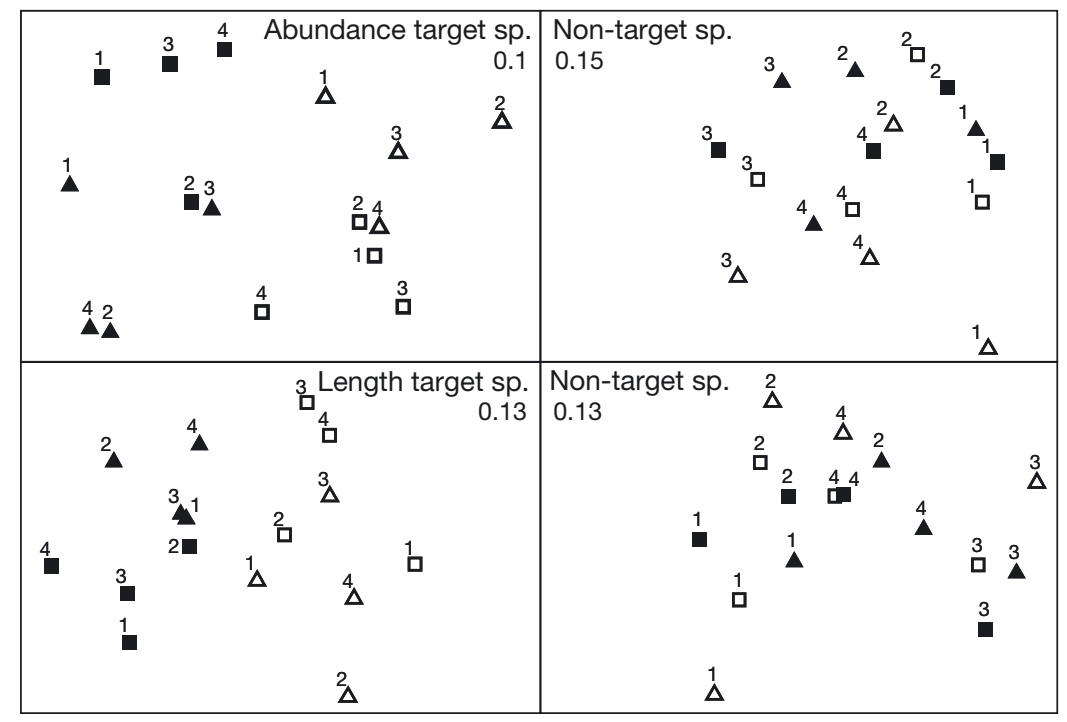

Fig. 6. NMDS plots based on mean abundance and mean length $(\mathrm{mm})$ centroids of target and non-target fish. Data were collected at 2 fished (open symbols) and 2 protected areas (shaded symbols) on 4 occasions during 2006-07 (indicated by numbers 1-4). For key to symbols showing locations see Fig. 2 legend. 2D MDS stress is indicated below plot headings 


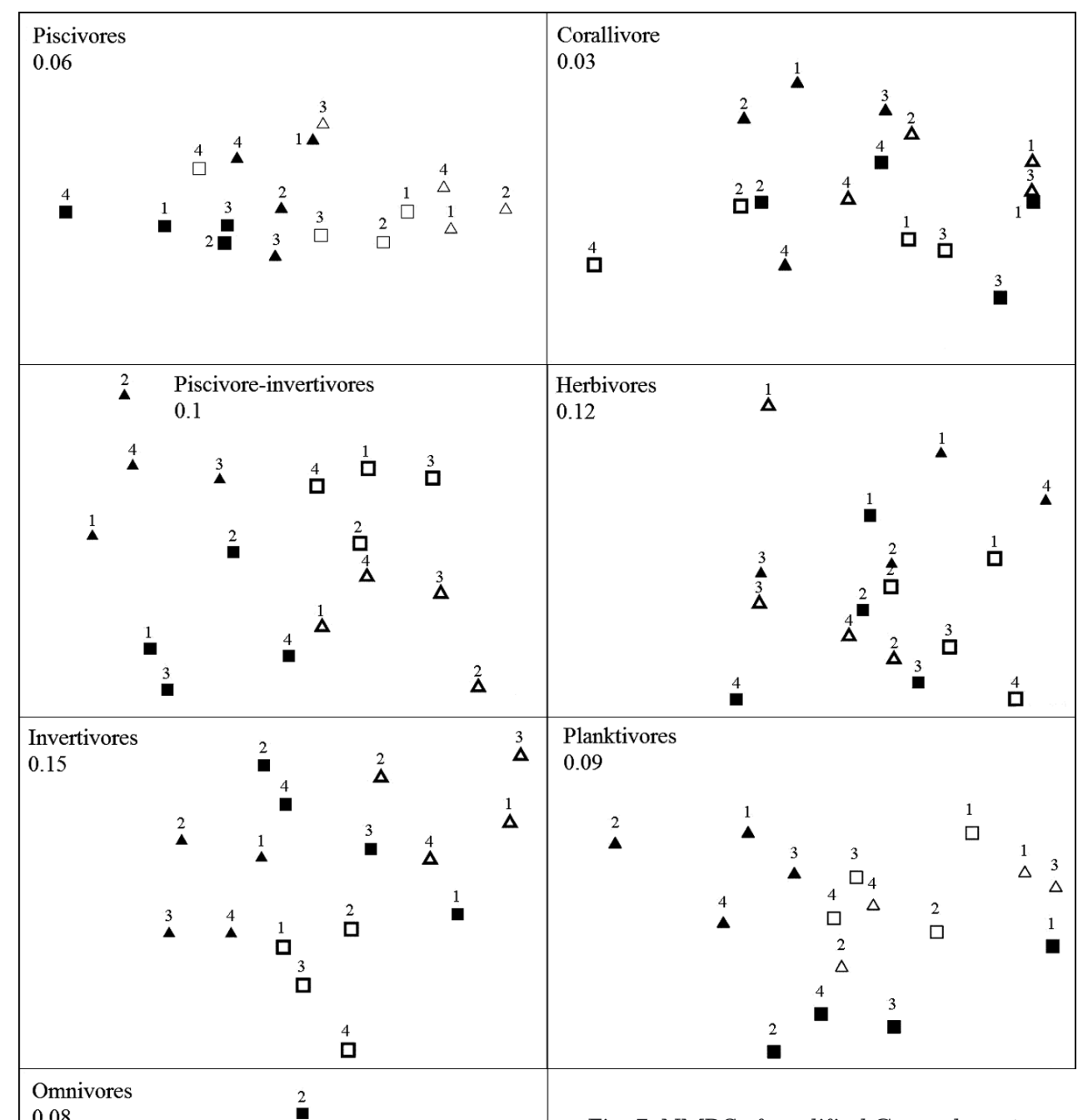

0.08

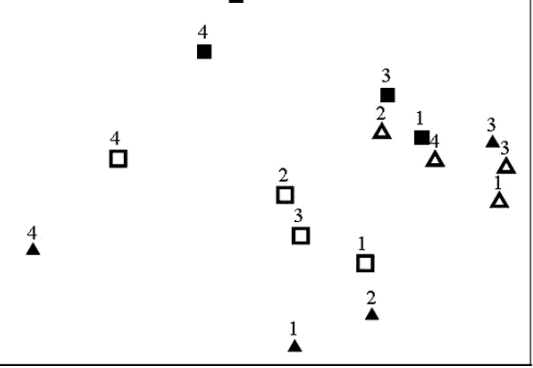

Fig. 7. NMDS of modified Gower $\log _{10}$ transformed abundance of trophic groups at 2 fished (open symbols) and 2 protected areas (shaded symbols), sampled on 4 occasions during 2006-2007 (numbers 1-4). For key to symbols showing locations see Fig. 2 legend. Values were based on centroids for each of the 4 sampling times, calculated using CAP analysis. 2D MDS stress is indicated below plot headings

blages were more abundant than in those that were fished. These sanctuaries have been in place since 1987, with consistent differences in target species abundance since then (Westera et al. 2003).

\section{Species responding to protection}

The presence of more and larger target species facilitates increased abundance and often larger individuals of particular non-target species. Driving these patterns were invertivores such as Thallasoma sp., Scolopsis bilineatus, Parupeneus indicus, Chaetodon lunula and Gomphosus varius, scavenging algal invertebrate omnivores like Abudefduf sexfaciatus, Scarus rubroviolaceous, Chlorurus sordidus, kyphosids, Acanthurus grammoptilus and the mutualistic Labroides dimidiatus. The ecological benefits of having intact healthy upper trophic levels, with more abundant and larger members of the lethrinid, lutjanid, carangid and serranid families, appeared to offset depletion of prey species from 


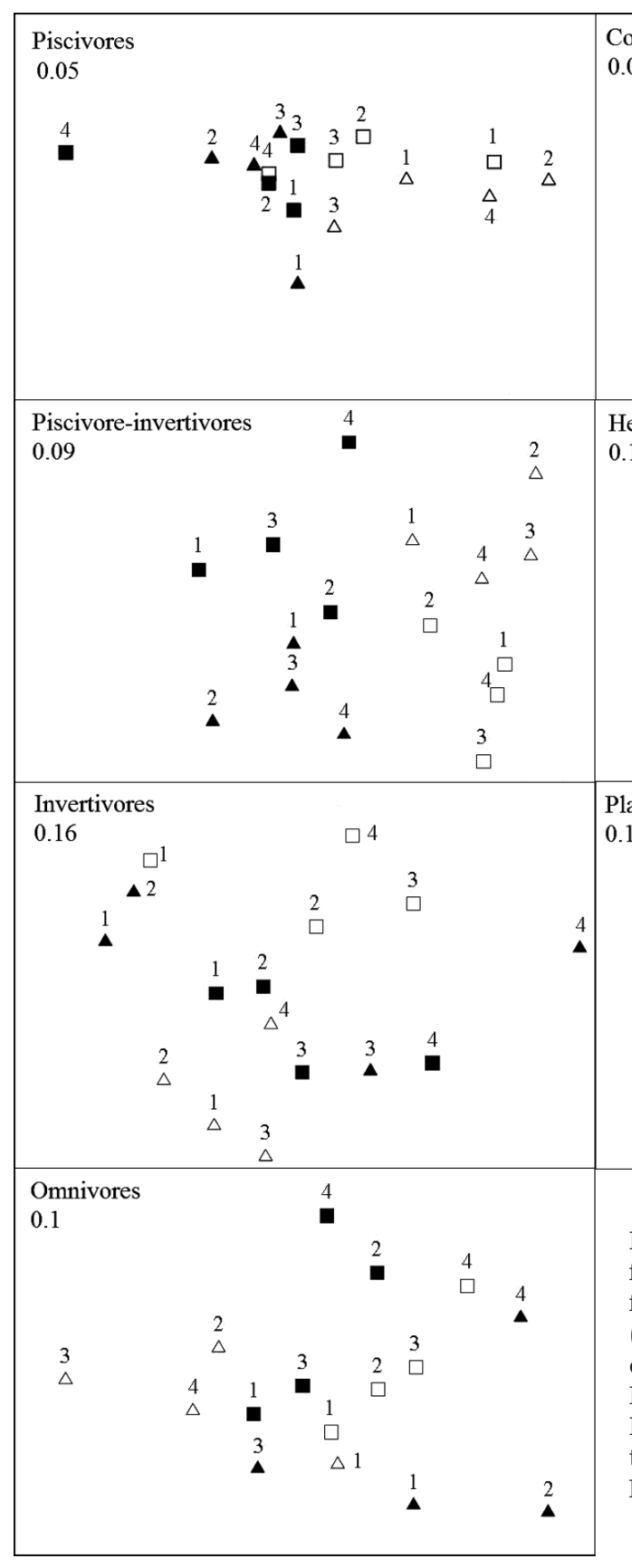

increased predation (Graham et al. 2003, Hixon \& Jones 2005). One explanation was that the increased activity of abundant target fish populations represented a considerable increase in the production and turnover of food and nutrients.

\section{Facilitation}

Lethrinids and carangids forage for food under rocks, rubble and sand and inadvertently expose

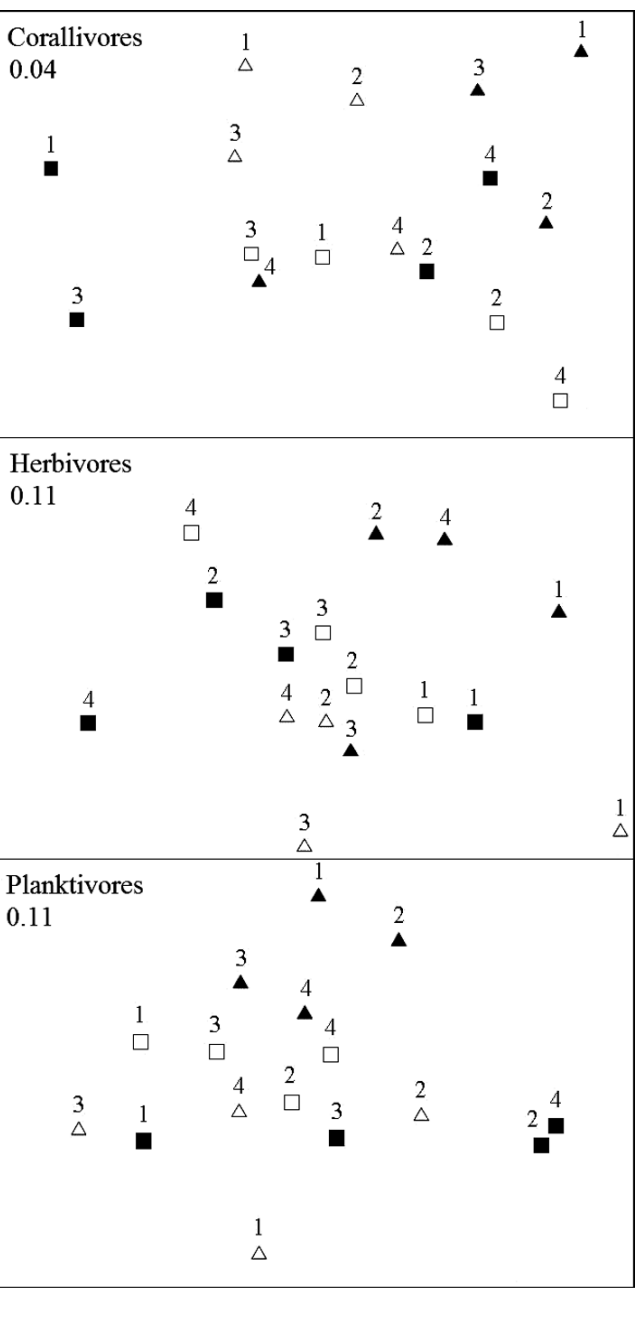

Fig. 8. NMDS of modified Gower $\log _{10}$ transformed mean length of trophic groups at 2 fished (open symbols) and 2 protected areas (shaded symbols) sampled on 4 occasions during 2006-07 (indicated by numbers 1-4. For key to symbols showing locations see Fig. 2 legend. Values were based on centroids for each of the 4 sampling times calculated using CAP analysis. 2-D MDS stress is indicated below plot headings

small crustaceans, worms, molluscs and other invertebrates. These otherwise inaccessible food items are quickly scavenged by opportunistic invertivores and omnivores. Likewise these larger predators prey on fish, crustaceans, echinoderms and molluscs. For example at Ningaloo, the diet of the highly abundant and ubiquitous Lethrinus nebulosus is composed almost solely of sea urchin (Westera et al. 2003, Farmer \& Wilson 2011). Scraps and leftovers from feeding activity together with increased faecal production is undoubtedly positively corre- 
Table 3. Results of 3-way PERMANOVA of effects of protection on mean biomass of coral reef fish. $\mathrm{p}<0.05$ in bold. For details see Table 1 legend

\begin{tabular}{|c|c|c|c|c|c|}
\hline Factors & df & SS & MS & Pseudo- $F$ & $\mathrm{p}$ \\
\hline \multicolumn{6}{|l|}{ Species } \\
\hline Lo & 1 & 11.426 & 11.426 & 0.537 & 0.997 \\
\hline Lo & 1 & 14.92 & 14.92 & 0.62 & 0.97 \\
\hline $\mathrm{Ti}$ & 3 & 34.95 & 11.65 & 1.72 & 0.001 \\
\hline $\operatorname{Pr}(\mathrm{Lo})$ & 2 & 47.8 & 23.92 & 5.89 & 0.001 \\
\hline $\operatorname{Pr}(\mathrm{Lo}) \times \mathrm{Ti}$ & 6 & 40.68 & 6.78 & 1.67 & 0.001 \\
\hline Res & 412 & 1672.5 & 4.06 & & \\
\hline Total & 427 & 1832.4 & & & \\
\hline \multicolumn{6}{|c|}{ Target species } \\
\hline Lo & 1 & 9.79 & 9.79 & 0.17 & 0.99 \\
\hline $\mathrm{Ti}$ & 3 & 45.00 & 15.00 & 1.84 & 0.001 \\
\hline $\operatorname{Pr}(\mathrm{Lo})$ & 2 & 113.19 & 56.60 & 10.44 & 0.001 \\
\hline $\operatorname{Pr}(\mathrm{Lo}) \times \mathrm{Ti}$ & 6 & 49.04 & 8.17 & 1.51 & 0.003 \\
\hline Res & 412 & 2231.8 & 5.42 & & \\
\hline Total & 427 & 2476.5 & & & \\
\hline \multicolumn{6}{|c|}{ Non-target species } \\
\hline Lo & 1 & 15.74 & 15.74 & 0.95 & 0.56 \\
\hline $\mathrm{Ti}$ & 3 & 33.22 & 11.07 & 1.80 & 0.001 \\
\hline $\operatorname{Pr}(\mathrm{Lo})$ & 2 & 33.28 & 16.64 & 4.32 & 0.001 \\
\hline $\operatorname{Pr}(\mathrm{Lo}) \times \mathrm{Ti}$ & 6 & 36.92 & 6.15 & 1.60 & 0.001 \\
\hline Res & 412 & 1586.9 & 3.85 & & \\
\hline Total & 427 & 1725 & & & \\
\hline \multicolumn{6}{|c|}{ Trophic groups } \\
\hline Lo & 1 & 7.15 & 7.15 & 0.93 & 0.51 \\
\hline $\mathrm{Ti}$ & 3 & 21.9 & 7.33 & 3.16 & 0.004 \\
\hline $\operatorname{Pr}(\mathrm{Lo})$ & 2 & 15.4 & 7.71 & 3.72 & 0.001 \\
\hline $\operatorname{Pr}(\mathrm{Lo}) \times \mathrm{Ti}$ & 6 & 13.9 & 2.32 & 1.12 & 0.29 \\
\hline Res & 412 & 853.84 & 2.07 & & \\
\hline Total & 427 & 921.39 & & & \\
\hline \multicolumn{6}{|c|}{ Overall (univariate ANOVA) } \\
\hline Lo & 1 & 0.1950 & 0.1950 & 0.0925 & 0.797 \\
\hline $\mathrm{Ti}$ & 3 & 4.389 & 1.463 & 2.2981 & 0.189 \\
\hline $\operatorname{Pr}(\mathrm{Lo})$ & 2 & 4.2137 & 2.1069 & 5.6309 & 0.004 \\
\hline $\operatorname{Pr}(\mathrm{Lo}) \times \mathrm{Ti}$ & 6 & 3.8248 & 0.63747 & 1.7038 & 0.116 \\
\hline Res & 412 & 154.15 & 0.37416 & & \\
\hline Total & 427 & 169.33 & & & \\
\hline
\end{tabular}

lated with increased abundance and length of lethrinids, lutjanids, serranids and carangids within marine reserve boundaries. This improves the food and nutrient budget of lower trophic levels. Fish from lower trophic levels, such as the detritivores and the many nominally herbivorous species, are likely to benefit from this increased food availability directly, and also indirectly as these nutrients benefit populations of algae and other marine plants, sessile and sedentary benthic invertebrates and plankton. All of these represent improved food availability and quality for particular fish. In a similar way, L. dimidiatus are likely to find more food available, i.e. the parasites, skin and other detritus found on target species that are more abundant and larger in protected areas. Mutualists like L. dimidiatus are likely to thrive in protected areas, as this study suggests. Not only do protected areas benefit target trophic groups such as piscivores and piscivore invertivores, but they consistently contained more abundant invertivores and planktivores.

\section{Exceptions}

There were however exceptions to these general trends. Kyphosids were smaller but more abundant at protected sites; as were Chromis viridis, which were by orders of magnitude the most abundant small fish at these locations. Although predation would likely increase significantly due to greater abundance of piscivores and piscivore invertivores, these levels would be approaching what are natural unfished levels and abundant prey like $C$. viridis have evolved to maintain viable populations in these conditions; otherwise they would no longer be extant.

\section{CONCLUSIONS}

Although this study indicates that fish were more abundant in protected areas, there were many individual species that responded in the opposite way. One reason why patterns of indirect effects were not clear at the level of trophic group could be because certain species might benefit from the presence of more targeted species while other functionally similar species respond negatively to protection in sanctuary zones through competitive release or other counterintuitive ecological responses. Lethrinus variegatus, Cheilinus trilobatus, Scarus schlegeli and Pomacentrus moluccensis were larger and/or more abundant at fished sites, Hemigymnus annulatus were more abundant at fished sites, but largest at Mandu sanctuary, and $H$. melapterus were more abundant but smaller at fished sites. Various ecological processes are likely to drive responses, including competition, size dependent predation, food and habitat availability. Response to protection is likely a function of individual species behaviour and habitat usage combined with life history and ecological inter-relationships with other species. All of these differ dramatically among the hundreds of species typical of coral reefs and are difficult to predict. At the reefscape scale, there are patterns in species and 
assemblage biomass that appear consistent with a suit of ecological processes maintained by protected areas. The responses reported here would likely prove useful indicators for guiding marine protected area science in the future.

\section{LITERATURE CITED}

Anderson MJ, Millar RB (2004) Spatial variation and effects of habitat on temperate reef fish assemblages in northeastern New Zealand. J Exp Mar Biol Ecol 305:191-221

Anderson MJ, Robinson J (2003) Generalised discriminant analysis based on distances. Aust NZ J Stat 45:301-318

Anderson MJ, Willis TJ (2003) Canonical analysis of principal coordinates: a useful method of constrained ordination for ecology. Ecology 84:511-525

Arias-González J, Done T, Page C, Cheal A, Kininmonth S, Garza-Pérez J (2006) Towards a reefscape ecology: relating biomass and trophic structure of fish assemblages to habitat at Davies Reef, Australia. Mar Ecol Prog Ser 320:29-41

Babcock RC, Shears NT, Alcala AC, Barrett NS and others (2010) Decadal trends in marine reserves reveal differential rates of change in direct and indirect effects. Proc Natl Acad Sci USA 107:18256-18261

Cappo M, Harvey E, Malcolm H, Speare P (2003) Potential of video techniques to monitor diversity, abundance and size of fish in studies of marine protected areas. In: Beumer JP, Grant A, Smith DC (eds) Aquatic protected areas: What works best and how do we know? World Congress on Aquatic Protected Areas. Australian Society for Fish Biology, Cairns, p 455-464

Cappo M, Speare P, De'ath G (2004) Comparison of baited remote underwater video stations (BRUVS) and prawn (shrimp) trawls for assessments of fish biodiversity in inter-reefal areas of the Great Barrier Reef Marine Park. J Exp Mar Biol Ecol 302:123-152

> Cassata L, Collins L (2008) Coral reef communities, habitats, and substrates in and near sanctuary zones of Ningaloo Marine Park. J Coast Res 24:139-151

Doherty PJ, Fowler AJ, Samoilys MA, Harris DA (1994) Monitoring the replenishment of coral trout (Pisces, Serranidae) populations. Bull Mar Sci 54:343-355

- Farmer B, Wilson S (2011) Diet of finfish targeted by fishers in North West Australia and the implications for trophic cascades. Environ Biol Fishes 91:71-85

Friedlander AM, Parrish JD (1998) Habitat characteristics affecting fish assemblages on a Hawaiian coral reef. J Exp Mar Biol Ecol 224:1-30

Friedlander AM, Brown EK, Monaco ME (2007) Coupling ecology and GIS to evaluate efficacy of Marine Protected Areas in Hawaii. Ecol Appl 17:715-730

Froese R, Pauly D (eds) (2014) FishBase. www.fishbase.org.

Graham NAJ, Evans RD, Russ GR (2003) The effects of marine reserve protection on the trophic relationships of reef fishes on the Great Barrier Reef. Environ Conserv 2:200-208
Harvey E, Fletcher D, Shortis MR, Kendrick GA (2004) A comparison of underwater visual distance estimates made by scuba divers and a stereo-video system: implications for underwater visual census of reef fish abundance. Mar Freshw Res 55:573-580

Hixon MA, Jones GP (2005) Competition, predation and density-dependent mortality in demersal marine fishes. Ecology 86:2847-2859

> Langlois TJ, Harvey ES, Fitzpatrick B, Meeuwig JJ, Shedrawi G, Watson DL (2010) Cost-efficient sampling of fish assemblages: comparison of baited video stations and diver video transects. Aquat Biol 9:155-168

Mumby PJ, Dahlgren CP, Harborne AR, Kappel CV and others (2006) Fishing, trophic cascades, and the process of grazing on coral reefs. Science 311:98-101

Russ GR, Cheal AJ, Dolman AM, Emslie MJ, Evans RD, Miller I, Sweatman H, Williamson DH (2008) Rapid increase in fish numbers follows creation of world's largest marine reserve network. Curr Biol 18:R514-R515

Sadovy Y, Domeier M (2005) Are aggregation-fisheries sustainable? Reef fish fisheries as a case study. Coral Reefs 24:254-262

Shears NT, Babcock RC (2002) Marine reserves demonstrate top-down control of community structure on temperate reefs. Oecologia 132:131-142

Shortis MR, Harvey ES (1998) Design and calibration of an underwater stereo-video system for the monitoring of marine fauna populations. Int Arch Photogramm Remote Sens 32:792-799

> Watson D, Harvey E, Anderson M, Kendrick G (2005) A comparison of temperate reef fish assemblages recorded by three underwater stereo-video techniques. Mar Biol 148:415-425

- Watson D, Harvey E, Kendrick G, Nardi K, Anderson M (2007) Protection from fishing alters the species composition of fish assemblages in a temperate-tropical transition zone. Mar Biol 152:1197-1206

> Watson DL, Harvey ES, Fitzpatrick BM, Langlois TJ, Shedrawi G (2010) Assessing reef fish assemblage structure: how do different stereo-video techniques compare? Mar Biol 157:1237-1250

> Westera M, Lavery P, Hyndes G (2003) Differences in recreationally targeted fishes between protected and fished areas of a coral reef marine park. J Exp Mar Biol Ecol 294:145-168

Willis TJ, Millar RB, Babcock RC, Tolimieri N (2003) Burdens of evidence and the benefits of marine reserves: putting Descartes before des horse? Environ Conserv 30: 97-103

> Wilson SK, Burgess S, Cheal A, Emslie M (2008) Habitat utilization by coral reef fish: implications for specialists vs. generalists in a changing environment. J Anim Ecol 77: 220-228

Wilson SK, Babcock RC, Fisher R, Holmes TH, Moore JAY, Thomson DP (2012) Relative and combined effects of habitat and fishing on reef fish communities across a limited fishing gradient at Ningaloo. Mar Environ Res 81:1-11 


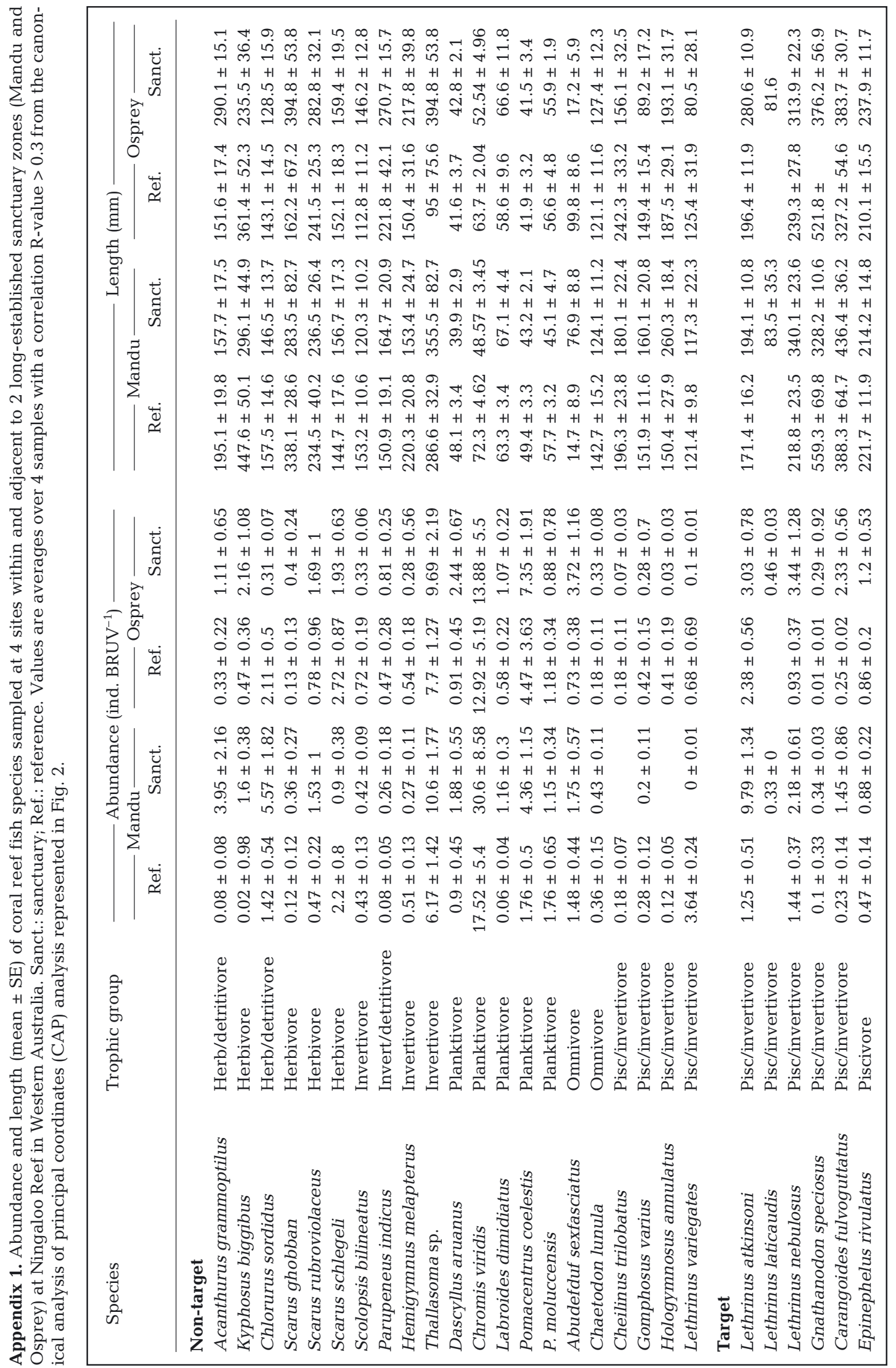

